\title{
Challenges on Collecting Smartphone Data in Cold Environments
}

\author{
Ella Peltonen, Vappu Schroderus, Parsa Sharmila \\ Center for Ubiquitous Computing, University of Oulu, Finland
}

firstname.lastname@oulu.fi

\begin{abstract}
Smartphones can be considered the cheapest and well-penetrated devices for collecting everyday human behaviour data. However, smartphones, as any battery-dependant electronic devices, face a number of problems when exposed to below-freezing conditions, from sudden crashes and decreased battery life to challenging usage experiences such as freezing fingers especially during prolonged periods of time. In this paper, we present the results of a user survey $(\mathrm{N}=130,59 \%$ female) exploring smartphone usage in below-freezing temperatures, including the problems caused by cold conditions and prevention mechanisms users could be willing to take to protect their device and user experience during winter months.
\end{abstract}

\section{CCS CONCEPTS}

- Human-centered computing $\rightarrow$ Mobile phones; Empirical studies in ubiquitous and mobile computing.

\section{KEYWORDS}

Smartphones, Temperature, Environment

\section{ACM Reference Format:}

Ella Peltonen, Vappu Schroderus, Parsa Sharmila. 2021. Challenges on Collecting Smartphone Data in Cold Environments. In Adjunct Proceedings of the 2021 ACM International foint Conference on Pervasive and Ubiquitous Computing and Proceedings of the 2021 ACM International Symposium on Wearable Computers (UbiComp-ISWC '21 Adjunct), September 21-26, 2021, Virtual, USA. ACM, New York, NY, USA, 3 pages. https://doi.org/10.1145/3460418.3479368

\section{INTRODUCTION}

Smartphones have become popular devices for activity tracking and an important human-behavioural data source due to their capacities to sense location and position as well as their easy-to-go UI and reasonable computing and communication capabilities [1]. However, in many parts of the world, diurnal and seasonal cycles produce cold temperatures down to negative degrees Celsius, which is out of the regular operating temperature of the majority of smartphones (for example, 0 to $35^{\circ} \mathrm{C}$ for Android and iPhone). Such cold temperatures are common in the Northern hemisphere, including Scandinavia, North America, and North Asia, where average January temperatures drop to $-10^{\circ} \mathrm{C}$ or colder (see Figure 1 . At the

Permission to make digital or hard copies of all or part of this work for personal or classroom use is granted without fee provided that copies are not made or distributed for profit or commercial advantage and that copies bear this notice and the full citation on the first page. Copyrights for components of this work owned by others than ACM must be honored. Abstracting with credit is permitted. To copy otherwise, or republish, to post on servers or to redistribute to lists, requires prior specific permission and/or a fee. Request permissions from permissions@acm.org.

UbiComp-ISWC '21 Adjunct, September 21-26, 2021, Virtual, USA

(c) 2021 Association for Computing Machinery.

ACM ISBN $\mathrm{xxx}-\mathrm{x}-\mathrm{x} x \mathrm{xx}-\mathrm{xxxxx}-\mathrm{x}$

https://doi.org/xx.xxxx/Xxxxxxx.xxxxxxx

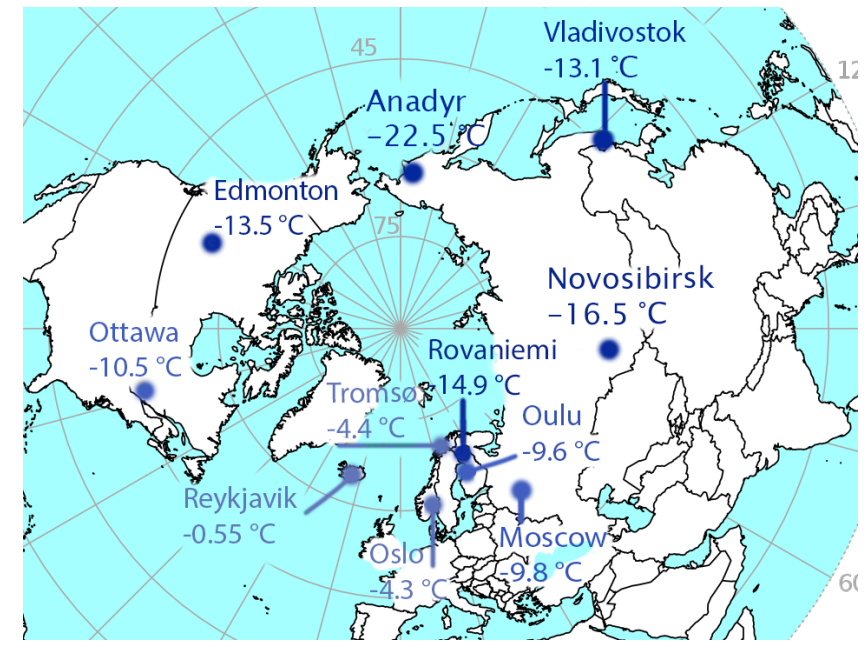

Figure 1: Smartphones are widely penetrated into locations where average January temperatures drop to $-10^{\circ} \mathrm{C}$ or colder.

same time, smartphone penetration rates of these countries are extremely high: Over $80 \%$ of adults use smartphones in Finland, Sweden, Canada, Norway, and Iceland in 2018, and 66\% in Russia $2019^{1}$.

People working, commuting or otherwise spending time outdoors cannot always avoid exposing their smartphones to below freezing temperatures. In many habitats with cold climates users frequently interact with their devices in outdoor settings. This exposure to cold is usually limited, but may be prolonged due to occupational requirements or recreational outdoor activities $[4,5]$. For example, certain tourism and travel apps - a popular way to augment reality with smartphones [11] - are used in Nordics to track northern lights and star gazing. In our study, $75 \%$ of participants reported regularly using their smartphones in cold conditions for commuting apps, such as maps, and $86 \%$ for making calls or sending messages. Other reported use cases were listening to music, playing games when waiting something, such as public transportation, and taking pictures of snowy landscapes or northern lights.

While the effects of cold environments have been previously studied from the perspective of smartphone usability and interactions [8], there is no general understanding of all the aspects of smartphone usage in cold outdoors and the challenges these conditions place for smartphones as a data source. Both overheating and cold can cause problems with device stability and battery life [10] making people unwilling to continue app use in the cold. Since cold conditions are known to deteriorate work performance [9] and

\footnotetext{
${ }^{1}$ www.statista.com
} 


\begin{tabular}{|c|c|c|c|c|c|}
\hline & $\begin{array}{l}\text { Faster battery } \\
\text { drainage }\end{array}$ & Apps crashing & OS crashing & $\begin{array}{l}\text { Interactions with } \\
\text { phone }\end{array}$ & Overheating \\
\hline $\begin{array}{l}\text { Number of responses } \\
\text { (in brackets) }\end{array}$ & $\begin{array}{c}\mathrm{d}(45) \\
\mathrm{f}(32) \\
\mathrm{a}(22) \\
\mathrm{b}(20) \\
\mathrm{g}, \mathrm{h}(1)\end{array}$ & $\begin{array}{c}\mathrm{d}(15) \\
\mathrm{b}(8) \\
\mathrm{a}, \mathrm{c}(1)\end{array}$ & $\begin{array}{l}\mathrm{d}(21) \\
\mathrm{b}(8) \\
\mathrm{a}(5)\end{array}$ & $\begin{array}{c}\mathrm{d}(34) \\
\mathrm{a}(29) \\
\mathrm{b}(17) \\
\mathrm{e}(4) \\
\mathrm{h}(2) \\
\mathrm{c}(1)\end{array}$ & a,b,d,h (1) \\
\hline $\begin{array}{l}\text { Mean number of reasons } \\
\text { to use phone in cold } \\
\text { (in brackets) }\end{array}$ & $\begin{array}{l}\mathrm{g}(5.00) \\
\mathrm{b}(3.35) \\
\mathrm{f}(3.18) \\
\mathrm{d}(3.02) \\
\mathrm{h}(3.0) \\
\mathrm{a}(2.90)\end{array}$ & $\begin{array}{c}\mathrm{b}(3.5) \\
\mathrm{d}(3.13) \\
\mathrm{a}, \mathrm{c}(1.0)\end{array}$ & $\begin{array}{c}\mathrm{b}(3.75) \\
\mathrm{d}(3.09) \\
\mathrm{a}(2.8)\end{array}$ & $\begin{array}{l}\text { e (3.75) } \\
\text { d (3.26) } \\
\text { a (3.03) } \\
\text { b (2.88) } \\
\text { c (1.0) } \\
\text { h (3.0) }\end{array}$ & $\begin{array}{c}\mathrm{b}(5) \\
\mathrm{d}(4.0) \\
\mathrm{h}(3.0) \\
\mathrm{a}(2.0)\end{array}$ \\
\hline $\begin{array}{c}\mathrm{SD} \\
\text { (in brackets) }\end{array}$ & $\begin{array}{l}\mathrm{a}(0.81) \\
\mathrm{f}(0.85) \\
\mathrm{b}(0.98) \\
\mathrm{d}(1.19)\end{array}$ & $\begin{array}{l}\mathrm{b}(0.53) \\
\mathrm{d}(1.06)\end{array}$ & $\begin{array}{l}\mathrm{a}(0.83) \\
\mathrm{b}(0.88) \\
\mathrm{d}(1.09)\end{array}$ & $\begin{array}{l}\mathrm{e}(0.95) \\
\mathrm{d}(0.99) \\
\mathrm{a}(1.01) \\
\mathrm{b}(1.11)\end{array}$ & - \\
\hline $\begin{array}{l}\text { a - As usual usage of phone } \\
\text { d- Try to keep phone tempe } \\
\text { g- Switch off internet }\end{array}$ & $\begin{array}{l}\text { ith no possible solu } \\
\text { ture normal }\end{array}$ & $\begin{array}{l}\text { Legend } \\
\text { on } \quad \mathrm{b} \text { - Avoid usin } \\
\mathrm{e} \text { - Carrying } \mathrm{h} \\
\mathrm{h} \text { - Use special }\end{array}$ & $\begin{array}{l}\text { phone in cold } \\
\text { ind warmer } \\
\text { phone cover }\end{array}$ & $\begin{array}{l}\text { c - Carrying backup pho } \\
\text { f - Carrying power bank }\end{array}$ & \\
\hline
\end{tabular}

Table 1: Summary of total number of responses against each precaution for each problem, mean number of reasons to use phone in cold and standard deviation of number of reasons to use phone in cold (the legend shows the precaution list).

impair interaction with devices [7], problems with device stability can further amplify the negative effects of cold temperature. While the pervasive community has taken steps to go "beyond the desktop" [3], only a handful of works have explored the use of devices in non-conventional environments. Indeed, more knowledge of smartphones and their usage in cold conditions is needed to secure around-the-year studies and data collection also in the Northern hemisphere.

In this paper, we present a survey of real-life user experiences when using smartphones outside in a cold environment. Our main research questions involve: 1) for what purpose people need to use their smartphones in cold? And 2) what are the main problems of using smartphones in cold? As a result, we discuss the usage reasons, problems faced due to the cold temperature, and prevention mechanisms taken to ensure fluent usage in cold. Even if we mainly discuss the smartphones, similar results could easily be applicable for different battery dependant devices, such as smart watches and other wearables.

\section{STUDY DESIGN AND PARTICIPANT OVERVIEW}

We run an online survey for people regularly using smartphones in below-freezing conditions. The survey was an anonymous Google form and was distributed to Facebook groups of people living in the Northern hemisphere. It contained the following fields: 1) reasons to use a smartphone in cold; 2) possible problems encountered when using a smartphone in cold; 3 ) and any precautions to allow the use of smartphones in cold. All the questions were open fields with some pre-defined examples. In addition, gender, age group, and country of residence were asked. No personal or identification information (such as names or emails) were collected. The study design follows the ethical guidelines of the Finnish National Board on Research Integrity (TENK).

We gathered 130 adult participants out of who 59\% identified as female, $36 \%$ male and the rest other genders or did not wish to specify. Age distribution was the following: $4 \%$ were from the group of 18-24 years of age, $46 \%$ were $25-34$ years of age, $32 \%$ were 35-44 years of age, and the rest older or did not wish to specify. The majority of people lived in Finland (around 80\%) where the survey was primarily distributed, but the study also contained responses from other countries experiencing winter conditions regularly such as Sweden, Canada, and Norway, but also other countries that can experience colder conditions at times or due to the high altitudes, such as Germany, Denmark, Japan, Switzerland, the UK, and the US.

The participants contributed with seven main types of usage reasons in cold: $86.1 \%$ use smartphones in cold for communication, such as making calls or sending messages. $74.6 \%$ of participants use smartphones for commuting, that is to use a phone for the purpose of the journey, such as road tracking maps, downloading transport tickets, checking bus schedules. $57.6 \%$ of participants listen to music or podcasts, and $27.6 \%$ play games on their phones. $23.1 \%$ use phones while they do outdoor winter sports and physical activities like skiing, trekking, jogging, hiking, aurora hunting. $20 \%$ have to use phones outdoor in cold for their work or study which includes field works and food delivery jobs. Capturing outdoor photos was mentioned by $6 \%$ of participants.

Some participants use smartphones for multiple purposes and functionalities when they are out in cold environments. These 
people are dependent on smartphones in their regular outdoor activities for multiple reasons at the same time, like listening to music while travelling and downloading the transport ticket or checking bus schedules. Some participants reported they take pictures when they are going for a walk, along with checking messages or road tracking map. Some participants did night-time photographing of stars and aurora with their phones and checked the aurora forecast and weather forecasts. Extended reality games were mentioned; games like Pokemon Go have become popular in recent years and require outdoor activities. In addition, traditional winter sports were mentioned as one of the most popular activities people do in countries of winter days. Skiing, hill trekking, and aurora hunting were some of the popular winter adventures reported in our study. To summarise, even our relatively small-scale study of 130 people highlighted various use cases for smartphones outdoors in cold environments, in addition to smartphones being used for basic reasons like making calls or checking messages. This underlines how multifunctional smartphones are, and how important different environmental conditions are to be considered.

\section{USAGE CHALLENGES IN COLD ENVIRONMENTS}

Using electronic devices out of their designed operational range - 0 to $35^{\circ} \mathrm{C}$ for most smartphones - does not come without drawbacks. The problems encountered by participants while using smartphones in cold temperature can be categorised into five criteria: $90.8 \%$ of the study participants suffered from battery running out unexpectedly faster than usual. $42.3 \%$ of participants faced problems interacting with a phone, mainly because of freezing hands. $21.5 \%$ of participants faced the problem of operating system crashing, $16.2 \%$ of participants suffered from crashed apps, and $3.1 \%$ of participants experienced device overheating. Unexpected OS crash, phone shutoff, unresponsive apps, or faster battery drainage are, indeed, considered to be common problems in cold environments [2]. Smartphone battery drainage in ambient cold temperature is caused by voltage drop in cold weather. Both Android and iOS users have reported suffering from unexpected shutoffs, even with the remaining battery capacity larger than $30 \%$ [2].

Besides the problems, the participants contributed precautions they take to handle those problems. We calculated the number of responses people provided for each problem and each precaution, results shown in Table 1. Our main findings can be summarised as follows: Faster battery drainage is handled by keeping the phone temperature normal (by any measure), carrying a power bank, or avoiding using a phone in cold. One person has come up with the solution of switching off the internet and using a special phone cover to keep the phone warm. To avoid apps or OS crashing unexpectedly, participants try to keep the phone temperature normal or avoid using the phone in cold - actions that are highly technical and not necessary very easy to implement. Interaction with smartphone mostly includes freezing hands or non-functional UI/screen for some moment. To avoid these, participants carry hand warmer (might also mean a specialised clove for interacting with the screen), use a special phone cover, or carry a backup phone. However, it is also notable - especially when considering using smartphones as a tracking device - that some users avoid using smartphones in cold at all due to the faced problems.

\section{CONCLUSIONS AND FUTURE WORK}

In this paper, we have presented a preliminary study of understanding how people use smartphones in cold temperatures. The challenges these people meet in their daily life can retard their willingness to invest in novel applications and participate in user studies during winter. Next, we are planning a field study to gather more comparison data of different user groups. For long-time effects, we plan to collect real-life data from actual smartphone usage through crowdsensing, which studies have demonstrated to be an effective tool for collecting large-scale real-world data [6]. We are also interested in the technical perspective of the cold's effects on smartphone battery, hardware, and software components, a topic that will be considered as its own study. This would require a different type of experimental setup with a controlled environment such as a climate chamber $[7,8]$.

\section{ACKNOWLEDGMENTS}

This research is supported by Academy of Finland 6Genesis Flagship (grant 318927) and Access, Privacy, Profiling, and Intelligent Applications (APPIA) Business Finland project.

\section{REFERENCES}

[1] Sang Min Ko, Won Suk Chang, and Yong Gu Ji. 2013. Usability principles for augmented reality applications in a smartphone environment. International journal of human-computer interaction 29, 8 (2013), 501-515.

[2] Youngmoon Lee, Liang He, and Kang G Shin. 2020. Causes and fixes of unexpected phone shutoffs. In International Conference on Mobile Systems, Applications, and Services. 206-219.

[3] Yong Liu, Jorge Goncalves, Denzil Ferreira, Simo Hosio, and Vassilis Kostakos. 2014. Identity crisis of ubicomp?: mapping 15 years of the field's development and paradigm change. In ACM International foint Conference on Pervasive and Ubiquitous Computing. ACM, 75-86.

[4] Tiina M Mäkinen, Lawrence A Palinkas, Dennis L Reeves, Tiina Pääkkönen, Hannu Rintamäki, Juhani Leppäluoto, and Juhani Hassi. 2006. Effect of repeated exposures to cold on cognitive performance in humans. Physiology \& Behavior 87, 1 (2006), 166-176.

[5] Florian'Floyd' Mueller and Sarah Jane Pell. 2016. Technology meets adventure: learnings from an earthquake-interrupted Mt. everest expedition. In Proceedings of the 2016 ACM International foint Conference on Pervasive and Ubiquitous Computing. ACM, 817-828.

[6] Ella Peltonen, Eemil Lagerspetz, Petteri Nurmi, and Sasu Tarkoma. 2015. Energy Modeling of System Settings: A Crowdsourced Approach. In the 2015 IEEE International Conference on Pervasive Computing and Communications (PerCom '15). $37-45$.

[7] Zhanna Sarsenbayeva, Jorge Goncalves, Juan García, Simon Klakegg, Sirkka Rissanen, Hannu Rintamäki, Jari Hannu, and Vassilis Kostakos. 2016. Situational impairments to mobile interaction in cold environments. In ACM Int. Foint Conference on Pervasive and Ubiquitous Computing. ACM.

[8] Zhanna Sarsenbayeva, Niels Van Berkel, Aku Visuri, Sirkka Rissanen, Hannu Rintamaki, Vassilis Kostakos, and Jorge Goncalves. 2017. Sensing cold-induced situational impairments in mobile interaction using battery temperature. ACM on Interactive, Mobile, Wearable and Ubiquitous Technologies 1, 3 (2017).

[9] Hannu Virokannas. 1996. Thermal responses to light, moderate and heavy daily outdoor work in cold weather. European journal of applied physiology and occupational physiology 72, 5-6 (1996), 483-489.

[10] Andreas Vlahinos and Ahmad A Pesaran. 2002. Energy efficient battery heating in cold climates. Technical Report. SAE Technical Paper.

[11] Zornitza Yovcheva, Dimitrios Buhalis, and Christos Gatzidis. 2012. Smartphone augmented reality applications for tourism. E-review of tourism research (ertr) 10 , 2 (2012), 63-66. 